\title{
Research
}

\section{Effect of Early and Conventional Sowings on Soybean Establishment Quality, Nodulation, and Early Biomass Development Under Inoculation with Rhizoctonia solani}

\author{
Jay Ram Lamichhane ${ }^{\dagger}$ (D) | Jean-Noël Aubertot |
}

INRAE, Université Fédérale de Toulouse, UMR AGIR, F-31320, Castanet-Tolosan, France

${ }^{\dagger}$ Corresponding author: J. R. Lamichhane; jay-ram.lamichhane@inrae.fr

Accepted for publication 10 February 2021
Funding

This study was funded by a starter grant of the INRAE's AgroEcoSystem Division to J. R. Lamichhane.

The author(s) declare no conflict of interest.

\begin{abstract}
Early sowing has potential to reduce negative impacts of summer drought on soybean productivity in southern Europe. However, performing early sowing into cool and moist soil conditions may increase risks of soilborne pathogens that cause damping-off disease. We investigated whether and to what extent soybean germination, emergence, nodulation, and early biomass growth was affected when inoculated with Rhizoctonia solani, an important causal agent of damping-off disease. We conducted this study through four complementary approaches: (i) in vitro laboratory tests, (ii) field experiments including two sowing dates (early and conventional), (iii) growth-chamber experiments, and (iv) modeling. The pathogen caused disease symptoms and significantly reduced $(P \leq$ 0.001 ) radicle growth in vitro but failed to cause disease under field or growthchamber conditions. No biological suppressiveness of the field soil to $R$. solani was found when tested in the growth chamber. Final field emergence rates ranged from 72 to $92 \%$ for early and conventional sowing, respectively, while those in the growth chamber ranged from 80 to $100 \%$. Under field conditions, abiotic stresses were the major causes of nonemergence while biotic stresses had only minor impact on seedling emergence. A significant effect of sowing date $(P<0.001)$ was observed on the average shoot and root length and on the number of average nodules per plantlet. The overall prediction quality of the SIMPLE model was very good for both sowing dates. The contrasts between laboratory and field experiments in terms of disease development, time to emergence, and early growth parameters are discussed.
\end{abstract}

Keywords: crop establishment, damping-off, modeling, seed germination, seedling emergence, soilborne pathogens, soil suppressiveness 
Increasing legume crop acreage to recover autonomy for plant proteins is a recent policy objective in the European Union (European Commission 2018). This is especially the case for soybean, for which the European Union's self-sufficiency rate is only at 5\%. The situation in France is very similar to the European Union in general, with a strong dependency on import of soybean from the American continent (FOP 2018). The 2014-2020 vegetable protein plan aims at reducing the country's plant protein import dependence by strengthening the competitiveness of legume crops in French cropping systems. Understanding key limiting factors affecting soybean production is of paramount importance to meet this objective.

Conventional sowing often exposes soybean to severe summer drought, mainly at the flowering phase, which is the most important yield constraint for this crop in southwestern France (Maury et al. 2015). Practicing early sowing may increase soybean yield, which is one of the research and policy objectives to increase soybean production in France and in the European Union. A recent study (Lamichhane et al. 2020b), based on multiyear field trials across different study sites, showed the practical feasibility of early sowing of soybean in southwestern France, without any negative impacts on the quality of crop establishment. However, this investigation did not consider the potential impact of biotic stresses affecting soybean establishment. Another study (Lamichhane et al. 2020a), conducted in the same region, did not find any important seed or seedling damage due to biotic stresses. Nevertheless, this study only considered the quality of soybean establishment with late sowing (i.e., end of May). Performing early sowing generally implies sowing into cool and moist soil conditions that are favorable for many soilborne pathogens that cause damping-off disease (Lamichhane et al. 2017). The disease consists of seed decay or rotting, prevention of seedling emergence after germination, or the wilting and collapse of seedlings at the soil level, also known as seedling blight (Ajayi-Oyetunde and Bradley 2017; Serrano and Robertson 2018). Damping-off of soybean, like that of many field crops in general, can be caused by many soilborne pathogens, including oomycetes (Rojas et al. 2017) and true fungi such as Rhizoctonia solani (Ajayi-Oyetunde and Bradley 2017), which are severe constraints for growers, especially in the United States. However, in the European Union, soybean stand losses due to soilborne pathogens are less frequent, although damping-off may be a constraint, especially in the northern European climate (Pannecoucque et al. 2018). In France, to the best of our knowledge, damping-off disease has not been frequently reported on field crops, which could be due to systematic chemical seed treatments (Lamichhane et al. 2020d). However, in the European Union, this disease may be an important production constraint for soybean, as in other parts of the world, especially when early sowing is performed and without any chemical seed treatment.

Crop models are important decision support tools to determine optimal sowing dates for field crops (Adnan et al. 2017; Dobor et al. 2016; Lamichhane et al. 2019, 2020a; Waha et al. 2012; Wolf et al. 2015). Previous studies tested crop models to determine optimal sowing dates for a number of crops, including maize and winter wheat (Adnan et al. 2017; Dobor et al. 2016). More specifically to the crop establishment phase, a crop emergence model called SIMPLE (Dürr et al. 2001) has been tested on a number of crops to determine the effect of sowing dates on the quality of crop establishment, in relation to seedbed physical conditions. These crops include sugar beet (Dürr et al. 2001), mustard (Dorsainvil et al. 2005), oilseed rape (Dürr et al. 2016), French bean (Moreau-Valancogne et al. 2008), and several catch crops (Constantin et al. 2015). Recently, the prediction quality of the SIMPLE model has been successfully evaluated for soybean (Lamichhane et al. $2020 a, b)$. Assessing the prediction quality of this model in relation to different soybean sowing dates would not only help to further confirm its robustness but also contribute to analyzing results of the field experiments.

The objectives of this study were to determine the effects of sowing time and $R$. solani inoculation on soybean germination, emergence, and growth parameters. We conducted this study through four complementary approaches: (i) in vitro experiments, (ii) field experiments, (iii) growth-chamber experiments, and (iv) modeling.

\section{MATERIALS AND METHODS}

\section{Soybean seed, fungal strain, and inoculum preparation}

Seed of the soybean cultivar ES Pallador belonging to group I (late maturity group) were used. The seed did not receive any treatments and were conserved at $4^{\circ} \mathrm{C}$ until their use.

$R$. solani (AG2-2IIIB) strain MIAE 1502 was used for the inoculation. This strain was previously isolated from infected sugar beet in northern France (Inokuti et al. 2019). We used this strain because no strain isolated from soybean was available from France, and strains isolated from soybean in other countries could not be used in the field. However, the host of origin was not a constraint because $R$. solani has a broad host range (Sneh et al. 1996). A 5-mm-diameter mycelial disc was excised from the pure stock culture and transferred to a $9-\mathrm{cm}$ plastic Petri dish containing $25 \mathrm{ml}$ of potato dextrose agar (PDA). The petri dish was incubated at $24 \pm 1{ }^{\circ} \mathrm{C}$ in an incubator for 4 days and the fungal culture obtained was directly used for in vitro experiments.

For in vivo experiments, the inoculum was prepared by adapting a method previously described (Scholten et al. 2001). Briefly, $500 \mathrm{~g}$ of commercial pearl millet seed were first autoclaved at $120^{\circ} \mathrm{C}$ for $30 \mathrm{~min}$ and soaked overnight in tap water using 2-liter Erlenmeyer flasks (1:1, vol/vol). The surplus of water was removed and the wet millet seed were autoclaved two times at $120^{\circ} \mathrm{C}$ for $30 \mathrm{~min}$ on two consecutive days. The sterilized millet seed were then inoculated with approximately 20 mycelial discs (each $5 \mathrm{~mm}$ in diameter) from a 3-day-old actively growing $R$. solani culture on PDA. The inoculated millet seed were incubated at $21^{\circ} \mathrm{C}$ for 12 to 14 days. The flasks were shaken every 2 to 3 days to avoid the formation of large, sticky clumps of seed and fungus and to ensure uniform colonization. The inoculum obtained was air dried and kept in plastic bags in the dark at $4^{\circ} \mathrm{C}$ until use.

\section{In vitro tests}

The experimental unit consisted of a Petri dish with five seeds, as described previously (Carmona et al. 2018). A 5-mm-diameter mycelial disc of this 4-day-old pure culture of the fungus was transferred again to the center of a $9-\mathrm{cm}$ plastic Petri dish containing the same amount of PDA. Soybean seed were sterilized in a $2.6 \% \mathrm{NaOCl}$ solution for $10 \mathrm{~min}$, followed by two rinses in sterile distilled water (10 min each). This was needed to avoid any potential contamination of seed due to seedborne pathogens. Five sterilized seeds were carefully placed at approximately $4 \mathrm{~cm}$ from the mycelial disc toward the periphery of the Petri dish. A control treatment 
without any fungal disc consisted of five seeds per Petri dish. The seed were assigned to the Petri dishes randomly. For inoculated and control treatments, the Petri dishes were laid out on a plastic tray in a completely randomized experimental design. Ten dishes (replications) per treatment were used. The Petri dishes were incubated in darkness at $24 \pm 1{ }^{\circ} \mathrm{C}$ in an incubator (Carmona et al. 2018). The experiment was repeated once.

Seed germination kinetics. The incubated Petri dishes were observed twice per day, beginning from the day after incubation, to annotate the number of germinated seed (Broders et al. 2007). A given seed was considered germinated when the radicle was $>0.5 \mathrm{~cm}$. At each observation, the number of germinated seed was noted and the Petri dishes were maintained in the incubator. The observations were continued until reaching a plateau (when the same number of germinated seed was observed for three consecutive observations).

Disease rating and measurement of radicle length. Seed in each Petri dish were assessed for the development of dampingoff symptoms (seed germination and necrosis in the radicle) 5 days after sowing (das). This rating was performed using a modified version of the severity scale proposed previously (Carmona et al. 2018), in which $\mathrm{A}=$ healthy germinated seed (no damping-off symptoms); $\mathrm{B}=$ germinated seed with $<50 \%$ necrosed portion of the radicle; $\mathrm{C}=$ germinated seed with 50 to $100 \%$ necrosed portion of the radicle; and $\mathrm{D}=$ nongerminated dead seed. The length of the each radicle was measured using a ruler for both inoculated and control treatments.

\section{Field experiments}

Study site and experimental design. The experiment was conducted at the Auzeville experimental station of INRAE $\left(43.53^{\circ} \mathrm{N}, 1.58^{\circ} \mathrm{E}\right)$ in 2019 . The soil had the following soil granulometry and chemical characteristics at the 0-to-30-cm soil horizon: clay at $0.31 \mathrm{~g} \mathrm{~g}^{-1}$, silt at $0.32 \mathrm{~g} \mathrm{~g}^{-1}$, sand at $0.37 \mathrm{~g} \mathrm{~g}^{-1}$, carbon at $0.072 \mathrm{~g} \mathrm{~g}^{-1}$, nitrogen at $0.008 \mathrm{~g} \mathrm{~g}^{-1}$, and organic matter at $0.0125 \mathrm{~g} \mathrm{~g}^{-1} ; \mathrm{pH}$ 8. Conventional tillage (30 $\mathrm{cm}$ in depth) was performed with a four-body plow in early September 2018 followed by a passage of a disc harrow in early March 2019 to prepare the seedbed.

Four treatments that resulted from the combination of two sowing dates (early and conventional) and two levels of $R$. solani inoculation (inoculation or not) were studied. The experimental design was a split plot (Preece et al. 1982), with two main plots associated with the two sowing dates and four subplots associated with the two levels of inoculation. Each of the four subplots was sown with soybean (ES Pallador) on a $45-\mathrm{m}^{2}$ area (15 m long and $3 \mathrm{~m}$ wide) on 11 March and 14 April for early and conventional sowings, respectively. For both dates, plots were sown at a $3-\mathrm{cm}$ sowing depth with 40 seeds $\mathrm{m}^{-2}$, and with $50-\mathrm{cm}$ interrow distance. For the two inoculated subplots, the $R$. solani inoculum was placed in the soil by adapting the method previously described by Chang et al. (2018). At sowing, previously prepared dry infested millet seed at $15 \mathrm{~g} \mathrm{~m}^{-2}$ (approximately $112.5 \mathrm{~g}$ per $15-\mathrm{m}$ row) was added to the soil. The viability of $R$. solani isolate was checked by successfully reisolating the pathogen from the millet seed. For control plots, we did not use uncolonized millet seed because they readily "bait-out" other nontarget soilborne pathogens present at a low level (Barbetti and Sivasithamparam 1987). Each of the four subplots was divided into four observational zones to repeat observations and measurements (hereafter referred to as subsubplots). Each subsubplot consisted of six rows. The two external rows and the first and last external meters of each row were not considered for measurements and observations in order to avoid potential edge effects on measured variables.

Seedbed characterization and sowing depth measurement. Seedbed structure of field crops is affected by cropping systems and climate (Lamichhane et al. 2021). Seedbed structure alters soil-seed contact (and the consequent seed imbibition process), rapidity of seed germination, and emergence (Blunk et al. 2021). In addition, seedbed structure plays an important role in seedling mortality rates, especially in a coarser seedbed (Gardarin et al. 2016). Therefore, we characterized seedbeds for both sowing dates using the method described by Lamichhane et al. (2020a).

Sowing depth is another important variable that affects time to emergence and, therefore, the duration of the heterotrophic crop growth (Lamichhane et al. 2018). The sowing depth (i.e., the mean distance between seed and soil surface) was measured by using a semidestructive measurement, as previously described (Lamichhane et al. 2020a). This measurement was performed on 100 seeds per subplot ( 25 seeds per subsubplot along four rows on the diagonal). The measurement was destructive meaning that the area used for this assessment was not used for future observations.

Seedbed weather. Soil temperature and water content were recorded using climate sensors $\left(\mathrm{ECH}_{2} \mathrm{O}\right.$ 5TM; METER Group, Inc.). The sensors were installed in the seedbed following sowing at three soil horizons ( 3 sensors/depth/main plot at $-3,-5$, and $-10 \mathrm{~cm}$ ). These sensors delivered hourly temperatures, measured by an onboard thermistor, along with accurate volumetric water content. Data were recorded from sowing until crop emergence. Rainfall data were obtained from an automatic meteorological station installed at the experimental site. The thermal time was calculated from sowing to emergence using the base temperature of soybean for germination: $4^{\circ} \mathrm{C}$ (Lamichhane et al. 2020a).

Because soil water content-transformed into water potentialwas an input variable of the SIMPLE model, sieved soil (5 mm) from the same field plots for both sowing dates was introduced into Richards' press to determine soil water-holding capacity at several pressures: $-0.1,-0.3,-1.0,-1.3$, and $-1.5 \mathrm{MPa}$. Three replicates for each pressure were made and the relationship between soil water content and water potential was established by fitting the van Genuchten equation (van Genuchten 1980).

Seed germination and seedling emergence rates. Depending on sowing dates and seedbed weather conditions, the number of germinated seed was counted every day beginning from 7 and 2 das for early and conventional sowings, respectively. Each seed germination measurement was independent of the following one, because the area used for a prior counting was not used for future observations. This was due to the semidestructive nature of the measurement because the act of uncovering the seed damages the fragile radicle and also alters the seed-soil contact, with an important impact on seed germination and seedling emergence. Seed were considered to have germinated successfully if the radicle was $>0.5 \mathrm{~cm}$ in length. The measurements were continued until reaching a plateau (the same number of germinated seed for three consecutive days) and when no rainfall was foreseen in the coming days. However, the measurements continued when rainfall was foreseen because rain triggers germination of those seed which did not germinate due to water stress (Lamichhane et al. 2020a).

Seedling emergence was counted in 4- $\mathrm{m}^{2}$ subplots (2 linear meters/row, 4 rows on the diagonal, for a total of $16 \mathrm{~m}^{2} / \mathrm{sub}$ plot) delimited with plastic pegs. Unlike the measurements 
conducted for sowing depth and seed germination that were semidestructive, these measurements were not semidestructive and were performed in the same delimited area from the beginning until the end. A seedling was considered emerged when cotyledons were clearly visible over the soil surface (Fehr and Caviness 1977). The counting was continued until reaching a plateau with no new emerging seedlings for several days.

Causes of nonemergence. Causes of nonemergence were identified at the vegetative cotyledon stage (i.e., when unifoliolate leaves unrolled sufficiently so the leaf edges are not touching) (Fehr and Caviness 1977). A previously proposed visual diagnostic key (Lamichhane et al. 2020a) that takes into account all biotic and abiotic stresses associated with nonemergence was used. Briefly, 40 empty points without seedling emergence per plot (10 along the row, four rows on the diagonal) were randomly selected. Gentle digging at each empty point was used to look for nongerminated seed or nonemerged seedlings. Once a seed or a seedling was found, its status was annotated according to its characteristics and the cause of nonemergence was noted.

Disease, nodulation, and plantlet biomass assessment. Young seedlings were sampled at V1 stage (i.e., fully developed leaves at unifoliolate nodes) (Fehr and Caviness 1977) to determine early growth characteristics and the impact of $R$. solani inoculation. In total, 240 seedlings per treatment (15 seedlings/row, four rows on the diagonal per subplot, and four subplots per treatment) were randomly uprooted, including the root system, put into paper bags, and brought to the laboratory. The seedlings were rapidly washed under running tap water to remove bigger soil particles from the roots. Seedlings were then floated in shallow trays of tap water and both roots and basal stem were visually scored independently, adapting a disease scale previously described (Chang et al. 2018), in which $\mathrm{A}=$ no lesions on root or the basal stem; $\mathrm{B}=$ small lesions $(<1 \mathrm{~cm})$ on root or basal stem; $\mathrm{C}=$ large lesions $(>1 \mathrm{~cm})$ on root or basal stem; D = sunken lesions on root or basal stem; and $\mathrm{E}=$ severe attacks on cotyledons with stunted growth.

Seedlings were then dried with paper towels and the number of nodules per plant was counted. In addition, using a ruler, the length of shoot (hypocotyl + node) and root was recorded for individual seedlings. Finally, shoots and roots from each row (i.e., 15 in number) were separated, put in paper bags, and dried at $60^{\circ} \mathrm{C}$ in an oven for 3 days. Dry shoot and root biomasses per plant were recorded (You and Barbetti 2017).

\section{Growth-chamber experiments}

$R$. solani isolates were found in French soils (Goll et al. 2014) and have been reported to cause crown and root rot of sugar beet in northern France (Inokuti et al. 2019). However, to the best of our knowledge, no damping-off disease of soybean, or of other field crops, due to this pathogen has been reported to date from the country. Therefore, our hypothesis was that there was potential existence of biological suppressiveness of the field soil to $R$. solani in southwestern France, one of the most important soybean-growing regions. To test this hypothesis, we conducted growth-chamber experiments using the same soil from the field plot, adapting a previously described method (Bongiorno et al. 2019).

Soil preparation and sowing conditions. Soil was sampled from the 0 -to-20-cm soil horizon of the same field plot and sieved through 5-mm holes. The soil was mixed with sterile white sand (sable de Fontainebleau) in the following soil/sand proportions: 100:0, 70:30, 50:50, and 30:70 (vol/vol). Half of this mixture for each proportion was sterilized in an autoclave at $120^{\circ} \mathrm{C}$ for $30 \mathrm{~min}$ to eliminate potential soilborne pathogens. A single autoclaving was performed because the soil was sampled from a field plot with no historical record of soilborne diseases. The previously prepared dry millet seed infested with $R$. solani inoculum, the same which was used for the field inoculation, was homogeneously mixed with each of these proportions $(10 \%$ inoculum $\mathrm{m} / \mathrm{m})$. Plastic pots (width $=$ $10.5 \mathrm{~cm}$ and height $=11.5 \mathrm{~cm}$ ) were filled with $500 \mathrm{ml}$ of each substrate and each pot was supplied with $100 \mathrm{ml}$ of osmosis water to achieve $20 \%$ humidity. The pots were incubated for 1 week at 20 and $15^{\circ} \mathrm{C}$ (day and night temperature, respectively) to allow the pathogen's development and establishment. This temperature range was used to mimic the early sowing field conditions of southwestern France. Treatments consisted of three factors: (i) soil/sand mixture at four different proportions, (ii) sterilized and unsterilized soil, and (iii) soil inoculated and uninoculated with $R$. solani. For each treatment, 4 pots were used, for a total of 64 pots, arranged in completely randomized blocks.

After 1 week, soybean seed (ES Pallador) that were preserved at $5^{\circ} \mathrm{C}$ in the cold chamber were placed at room temperature for 1 $\mathrm{h}$ before sowing. Five soybean seeds/pot were sown at a $3-\mathrm{cm}$ sowing depth and the holes were slightly covered with the same substrate. The seed were sown approximately $3 \mathrm{~cm}$ from the margin of the pot, while the fifth seed was sown in the middle of the pot. The pots were then incubated at a photoperiod of 12 and 12 $\mathrm{h}$ and temperature of 20 and $15^{\circ} \mathrm{C}$, day and night, respectively, and $70 \%$ relative air humidity to mimic early sowing field conditions. Pots were watered twice a week to maintain a constant humidity level.

Emergence dynamics of soybean. The number of emerged seedlings was counted every day beginning from 3 das. A seedling was considered to have emerged once the cotyledons were above the soil surface (Fehr and Caviness 1977). Counting halted when the emerged seedlings remained the same for three consecutive days.

Incidence and severity of pre- and postemergence dampingoff. Following the completion of emergence, a careful inspection of seed or radicle parts was performed to find nongerminated or nonemerged seedlings. To this end, the pots were gently emptied to recover seed or seedling parts, which were washed under tap water. Disease assessment was performed using the following scale: $0=$ sprouted and healthy seed (no necrosis or symptoms of dampingoff); 1 = unsprouted and rotten seed; 2 = germinated seed with $<25 \%$ necrosis on radicle or hypocotyl; $3=$ germinated seed with 25 to $50 \%$ necrosis on radicle or hypocotyl; $4=$ germinated seed with 50 to $100 \%$ necrosis on radicle or hypocotyl; and $5=$ dead nongerminated seed. Emerged seedlings were sampled and the rating for a possible presence of postemergence damping-off was performed using the same scale described above for the field experiment. Reisolations were made from inoculated plants onto PDA to confirm the viability of the inoculated fungal strain.

Nodulation and plantlet biomass assessment. The same procedure used for the field experiment described above was used to determine the number of nodules, shoot and root biomass, and length.

\section{Overview of the SIMPLE crop emergence model}

A comprehensive description, including the functioning of the SIMPLE model and the list of equations, parameters, and input and output variables, has been previously provided (Dürr et al. 2001). In brief, this stochastic model predicts germination and emergence processes after sowing as a function of seed and seedling characteristics, sowing depth distribution, 
and seedbed physical conditions (temperature, humidity, and structure) under the influence of a weather scenario. The model has previously been parameterized and satisfactorily evaluated for a number of crop species: wheat, sugar beet, flax, mustard, French bean, oilseed rape (Dorsainvil et al. 2005; Dürr et al. 2001, 2016; Moreau-Valancogne et al. 2008); soybean (Lamichhane et al. 2020a); several catch crops (Constantin et al. 2015); and the plant model Medicago truncatula (Brunel et al. 2009). Here, we mainly focus on the model's key features and the input variables measured for a soybean crop, without presenting the already published equations.

SIMPLE creates three-dimensional representations of seedbeds with sowing depth distribution and the size, number, and position of soil aggregates as input variables. Soil temperature at the mean sowing depth and daily soil water potential in layers of 0 to 3,3 to 5 , and 5 to $10 \mathrm{~cm}$ are also used as input variables for simulations, along with plant characteristics for germination and seedling growth. Seed are placed into virtual numerical seedbeds at random using a sowing-depth distribution provided by the user. The model predicts germination and emergence, seed by seed, at a daily time step. The time required for germination of the seed is chosen at random in a distribution of thermal times needed to reach germination for the considered seed lot. Hydrothermal time since sowing is calculated using a base temperature for germination $(T b)$, provided that the soil water content at the seed sowing depth is above a base water potential $(\Psi b)$. The $T b$ and $\Psi b$ constants for germination are input variables. If seed has not germinated after a given time (often fixed at 30 days), the model considers that it will never germinate. To better include the effect of early water stress on seedling growth, we added a water stress function to the SIMPLE model, which reduces emergence after germination (Constantin et al. 2015). With this function, the fate of seedlings is determined by considering soil water potential in the soil layer in which the radicle grows in the 2 days following germination. If it is lower than $\Psi b$, the seedling does not emerge and dies the following day. If this is not the case, the time it takes for the seedling to reach the soil surface after germination is calculated by SIMPLE based on its seed's sowing depth, the length of the pathway the shoot takes through the aggregates to reach soil surface, and the shoot's elongation function, whose parameters are input variables. The probability of the seedlings remaining blocked under aggregates depends on the size and position of the soil aggregates in the seedbed (i.e., lying on the surface or below it). Soil surface crusting depends on cumulative rainfall after sowing; a proportion of seedlings remains blocked under the crust depending on daily crust water content (dry or wet soil surface). Simulations were run for 1,000 seeds to predict the emergence rate over time, including final emergence rates. The causes of nonemergence simulated by SIMPLE are (i) nongermination, (ii) death of seedlings caused by water stress after germination, and (iii) mechanical obstacles (soil aggregates or a soil crust). The SIMPLE model does not consider biotic stresses such as pests and diseases or the effect of high temperatures, which could inhibit germination.

\section{Statistical analyses}

Statistical criteria for laboratory, growth-chamber, and field experiments. Germination and emergence rates at each observation and their final rates were averaged. For germination and emergence, the number of average germinated seed at each observation was divided by the total number of seed tested (in vitro and the growth chamber) or planted (the sowing density under field and growth-chamber experiments) per treatment. The value obtained was multiplied by 100 to get the rates of germinated seed at each observation as well as the final rates of germination and emergence. The same procedure was used to calculate the rates of nonemergence. All of these calculations were performed using Microsoft Excel 2010.

The effect of different treatments on the tested variables was analyzed using one-way analysis of variance (ANOVA) followed by a Tukey's honestly significant difference posthoc test. Two-way ANOVA was applied to determine any possible interaction effects between treatments on the tested variables. All statistical analyses were applied using software R (Hothorn and Everitt 2009).

Statistical criteria used for model evaluation. Three statistical criteria-model efficiency $(\mathrm{EF})$, root mean square error of prediction (RMSEP), and mean deviation (MD) — were calculated to assess the quality of model predictions for germination and emergence.

$$
\begin{gathered}
E F=1-\frac{\sum_{j=1}^{n}\left(P_{j}-O_{j}\right)^{2}}{\sum_{j=1}^{n}\left(O_{j}-\bar{O}\right)^{2}} \\
R M S E P=\sqrt{\sum_{j=1}^{n}\left[\left(P_{j}-O_{j}\right)^{2} / n\right]} \\
M D=\frac{1}{n} \sum_{j=1}^{n}\left(P_{j}-O_{j}\right)
\end{gathered}
$$

$P_{j}$ and $O_{j}$ are predicted and observed values, respectively; $n$ is the number of observations; and $\bar{O}$ is the mean of observed values. EF (ranges from $-\infty$ to 1 ) represents model accuracy relative to the mean of observed data and $=1$ for a perfect model prediction. As EF approaches 1, observed and predicted values converge, indicating model accuracy. MD provides model deviation that is a measure of the tendency of the model to under- or overestimate predicted values compared with observations. A negative value indicates that the majority of predicted values are lower than the observed ones.

\section{RESULTS}

\section{In vitro tests: Seed germination kinetics, disease severity index, and radicle growth}

Seed germination rates, disease severity, and radicle length with and without inoculation with $R$. solani are reported in Figures 1 and 2. Overall, seed germination was completed after $64 \mathrm{~h}$ from incubation for both treatments. The final germination reached $94 \%$ for the inoculated seed, whereas it was $98 \%$ for the noninoculated ones. No statistically significant differences $(P>0.05)$ were observed between seed inoculated without and with the fungal pathogen in terms of germination courses and final rates (Fig. 1A). In contrast, statistically significant differences $(P \leq 0.001)$ were observed between inoculated and noninoculated treatments in terms of disease incidence, disease severity, and radicle length (Fig. 1B). The average radicle length was 1.20 and $5.17 \mathrm{~cm}$ for inoculated and noninoculated treatments, respectively (Fig. 1C). Inoculated seed were severely affected by the disease, which affected radicle length (Fig. 2). All noninoculated seed remained healthy. 


\section{Field experiments}

Seedbed characterization and sowing depth measurement. The seedbed had 27 and $23 \%$ of soil aggregate mass of $>20 \mathrm{~mm}$ in diameter for early and conventional sowings, respectively. No soil aggregate $>30 \mathrm{~mm}$ in diameter was found under buried, partially buried, or totally buried conditions. Soil aggregates smaller than this diameter were found under all of these spatial distributions in the seedbed.

The sowing depth varied between 1 and $4 \mathrm{~cm}$ for the early sowing and ranged from 1.5 to $5 \mathrm{~cm}$ for the conventional sowing. Overall, 45 and $50 \%$ of seed were located between 2.5 and $3.5 \mathrm{~cm}$ of depth for early and conventional sowings, respectively.

Weather data. The average seedbed temperature at the sowing depth (i.e., $-3 \mathrm{~cm}$ ) from sowing to emergence was $12 \pm 3$ and $15 \pm 4{ }^{\circ} \mathrm{C}$ for early and conventional sowings, respectively. The cumulated rainfall from sowing to emergence was 67 and $104 \mathrm{~mm}$ for early and conventional sowings, respectively. The seedbed in the early sowing was dry because there was only $9 \mathrm{~mm}$ cumulated rainfall for 3 weeks after sowing. Consequently, three irrigation interventions (each approximately $5 \mathrm{~mm}$ ) were performed on 7, 9, and 15 das for the early sowing to avoid seedling death due to water stress in the seedbed. The mean daily seedbed humidity at the sowing depth ranged from 4 to $16 \%$ for early sowing and from 6 to $18 \%$ for late sowing. The threshold at which the water stress began in the seedbed, calculated by the relationship between the measured and fitted data, corresponded to $10 \%$ (Fig. 3).
Seed germination and seedling emergence rates. No disease development occurred under field conditions. No differences between the inoculated and noninoculated treatments were observed for both sowing dates. Therefore, data on seed germination and seedling emergence dynamics from both treatments were pooled and analyzed by sowing date.

Seed germination and seedling emergence courses and final rates under field conditions for early and conventional sowings are presented in Figure 4. Germination was very slow for early sowing and it took 24 das (214 degree-days [dd]) to reach maximum germination rate (i.e., 100\%) compared with only 8 das $(96 \mathrm{dd})$ required for conventional sowing. Seedling emergence for the early and conventional sowing started at 24 das (207 dd) and 11 das (130 dd), respectively. Likewise, the rate of final seedling emergence was 72 and $92 \%$ for the early and conventional sowing, respectively. It took 37 das (313 dd) for the early sowing versus only 22 das (260 dd) for the conventional sowing to reach the final emergence rate.

Causes of nonemergence. The nonemergence rates of seedlings observed in the plots were 28 and $8 \%$ for early and conventional sowings, respectively. Seedling mortality due to soil aggregates was the most important cause of nonemergence for both sowing dates, with 28 and $6 \%$ of mortality for early and conventional sowings, respectively. However, $2 \%$ of seedlings were also found attacked by soil pests for the conventional sowing.

Disease, nodulation, and plant biomass assessment. No symptoms of damping-off disease were observed under field
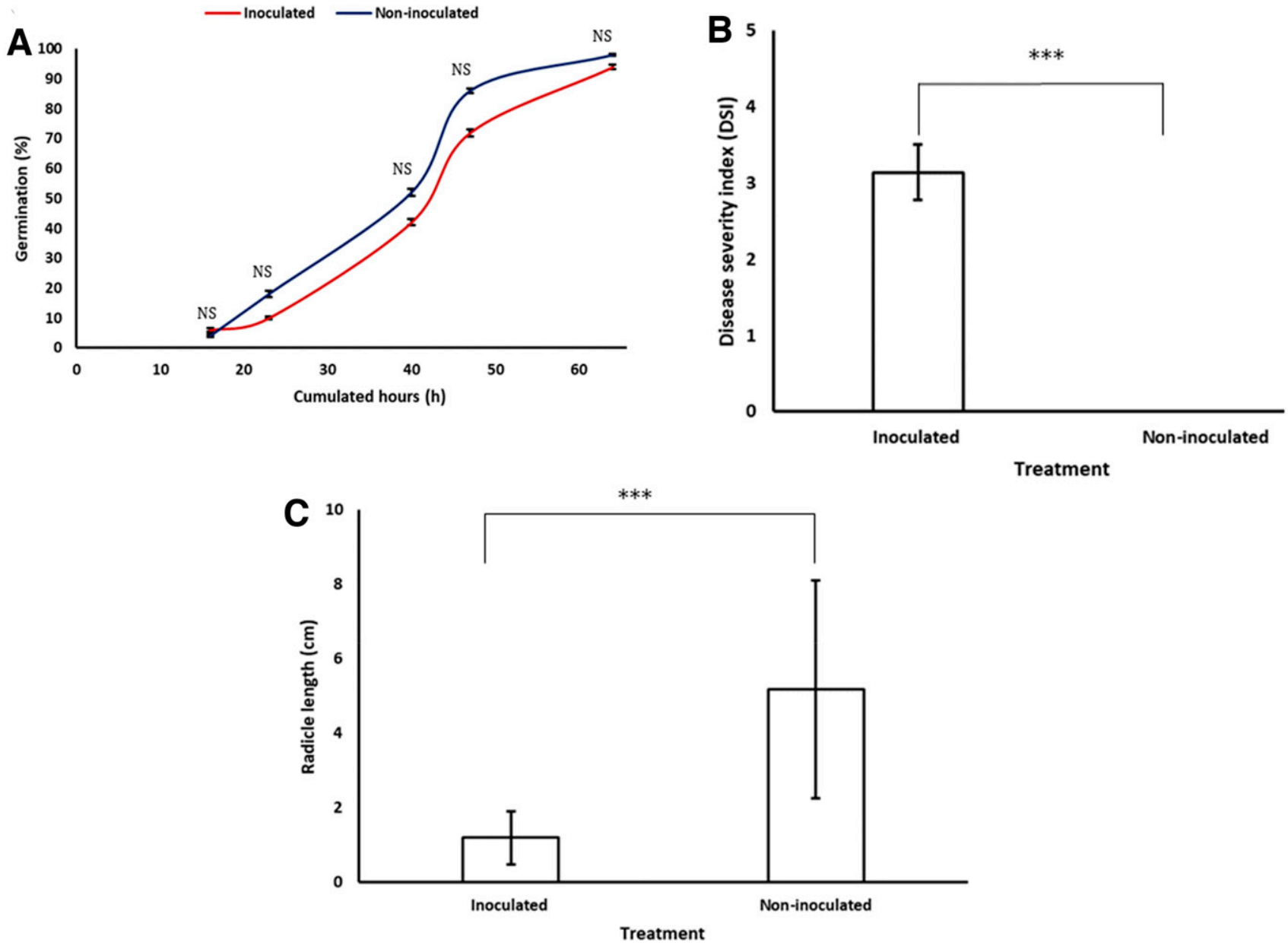

FIGURE 1

A, In vitro seed germination dynamics of soybean; $\mathbf{B}$, disease rating; and C, radicle length with and without inoculation with Rhizoctonia solani. Error bars on the graph represent standard deviation. NS $=$ not significantly different at $P<0.05$ and asterisks $(* * *)$ indicate $P<0.001$. 
conditions for early or conventional sowings. No fungal growth was observed on PDA when attempts to reisolate the inoculated fungal strain were made from root parts. Average number of nodules per plant was 6 for both treatments for early sowings, whereas it was 4 and 6 for inoculated and noninoculated treatments, respectively, for conventional sowing. Statistically significant differences of sowing date $(P<0.001)$, treatment $(P<0.05)$, and sowing date-treatment interactions $(P<0.01)$ were found on the number of average nodules per plant.

The average shoot and root length was lower (i.e., $9 \mathrm{~cm}$ each) for early sowings compared with the conventional sowings (i.e., 11 and $10 \mathrm{~cm}$, respectively). A statistically significant effect of sowing date $(P<0.001)$ was observed on the average shoot and root length whereas no statistically significant difference of inoculation $(P=0.49$ and 0.43$)$ and sowing date-inoculation interactions $(P=0.30$ and 0.10$)$ was observed on the average root and shoot lengths, respectively. The average dry shoot biomass was $3 \mathrm{~g} /$ plant and it did not differ among the sowing dates or inoculations. The average dry root biomass ranged from 0.67 to $0.75 \mathrm{~g} / \mathrm{plant}$. Only significant differences of sowing date $(P<0.01)$ were found on the average dry root biomass.

\section{Growth-chamber experiments}

Rates of soybean emergence. Emergence dynamics of soybean in relation to soil mixture and treatments are reported in Figure 5. There was no significant effect $(P>0.05)$ of soil mixture on time to emergence. In contrast, a significant effect

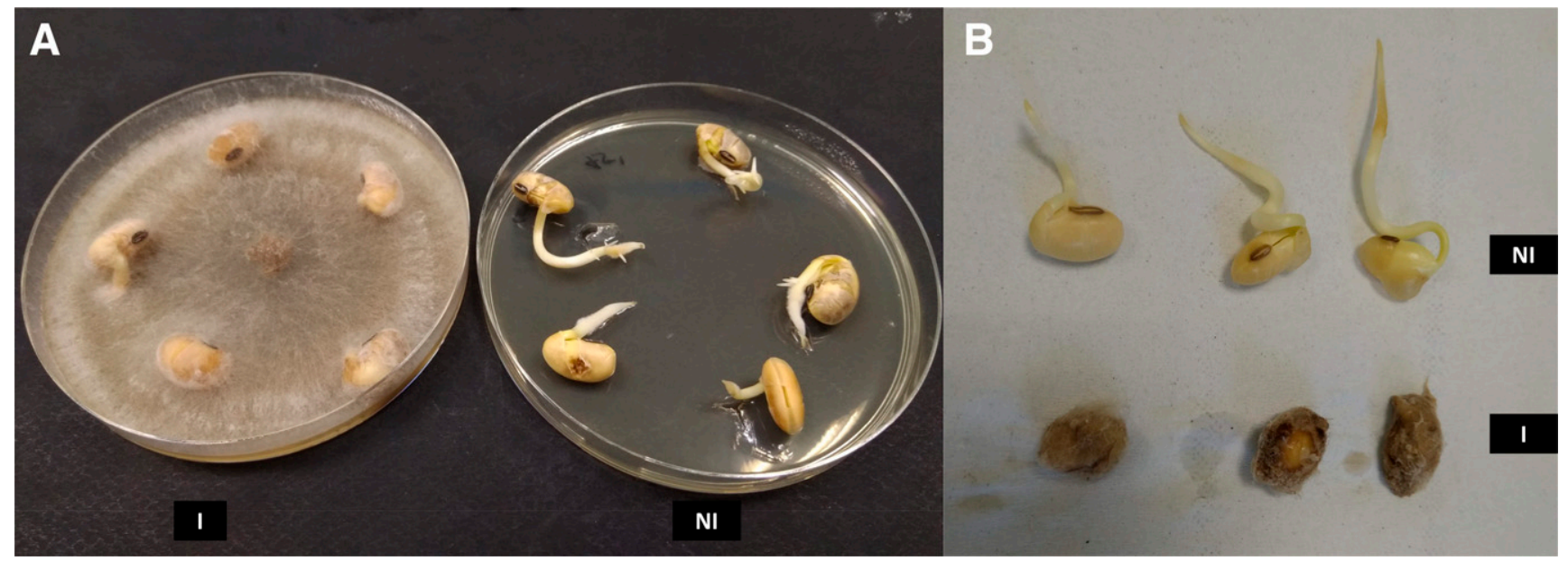

\section{FIGURE 2}

A, Characteristic symptoms of preemergence damping-off caused by Rhizoctonia solani and $\mathbf{B}$, the consequent impact on radicle elongation. I and $\mathrm{NI}=$ inoculated and noninoculated treatments, respectively.

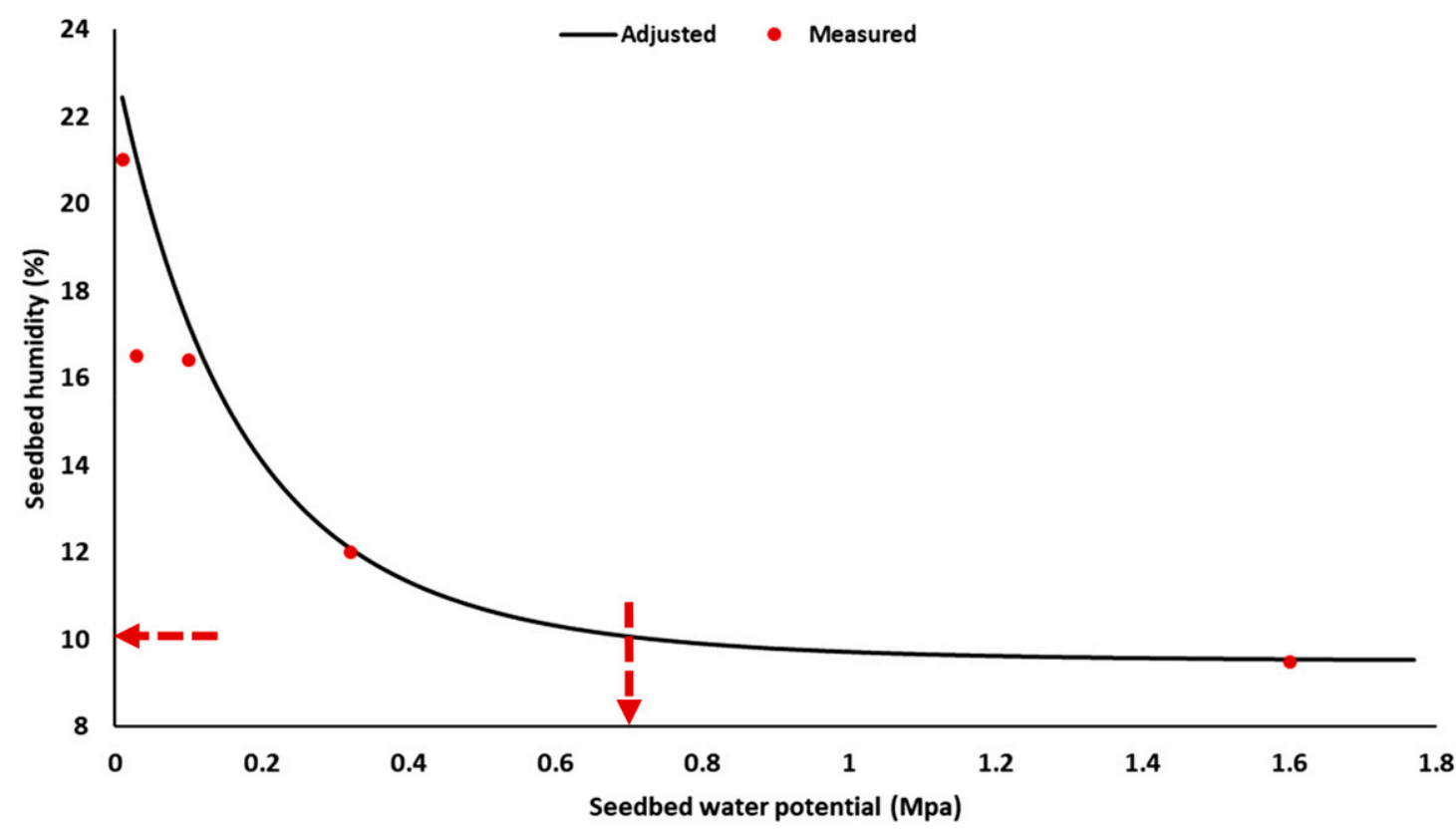

FIGURE 3

Soil water characteristic curve showing relationship between the seedbed water potential and the water content. The water stress threshold was determined based on the measured data and the fitted model of van Genuchten (1980). The vertical arrow on the x-axis represents the seed water potential while the horizontal arrow on the $y$-axis indicates the threshold at which the water stress began in the seedbed (corresponding to $10 \%$ humidity). The threshold value was the same for both sowing dates given the same soil texture. 
$(P<0.01)$ of soil sterilization and pathogen inoculation was observed on time to emergence up to 8 das. Likewise, there was a significant soil mixture-treatment interaction effect $(P<0.001)$ on time to emergence. In contrast, no significant effect $(P>0.05)$ of soil mixture, treatments, or soil mixture-treatment interaction was found on the final emergence rates of soybean under growthchamber experiments. It took 10 to 11 das to attain the maximum emergence rates, which ranged from 80 to $100 \%$ depending on the treatment types.

Dry shoot and root biomass. Dry shoot and root biomass in relation to soil mixture and treatments are reported in Table 1. The appearance of the first node and complete spreading of the unifoliate leaves (i.e., V1 stage) occurred 2 weeks after sowing. Soil mixture did not have any significant effect $(P>0.05)$ on dry shoot or root biomass whereas the treatment type had a significant impact $(P<0.001)$ on them. In the mixture without the sand (i.e., 100:0 soil/sand proportion), the plant dry weight (i.e., both the hypocotyl and radicle) was significantly higher $(P<0.01)$ under inoculated conditions compared with that under the noninoculated one. No significant soil mixture-treatment interaction effect $(P>0.05)$ was observed on shoot and root dry biomass. Average dry shoot mass ranged from 0.50 to $0.90 \mathrm{~g}$ while average dry root biomass ranged from 0.11 to $0.22 \mathrm{~g}$.

Shoot and root length. Average shoot and root length in relation to soil mixture and treatments are reported in Table 2. Soil mixture did not have any significant effect $(P>0.05)$ on shoot length whereas it had a significant effect $(P<0.001)$ on root length. The treatment type had significant impact $(P<0.001)$ both on shoot and root length. There was also a significant soil mixture-treatment interaction effect $(P<0.01)$ on shoot and

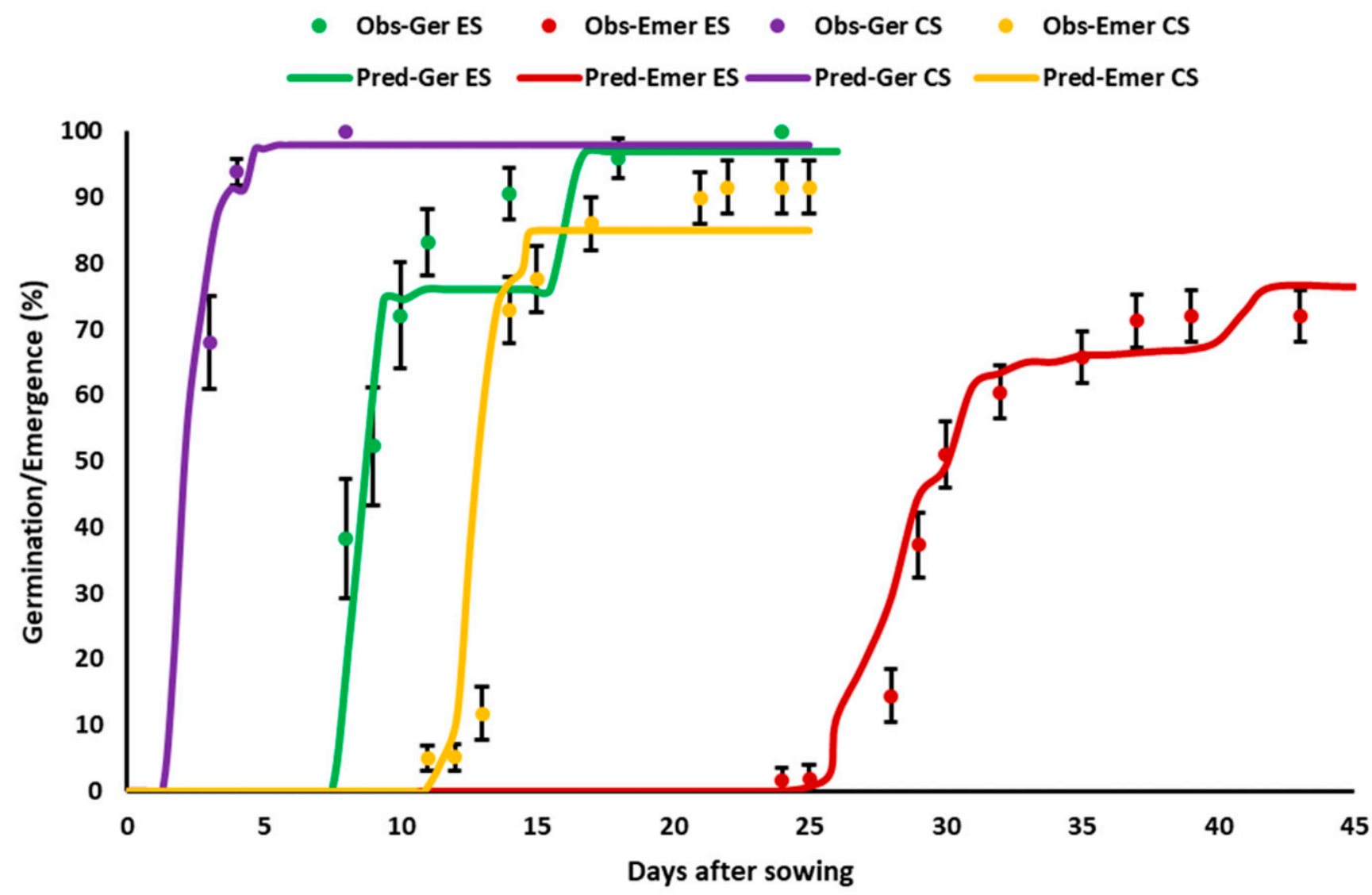

\begin{tabular}{|c|c|c|c|c|}
\hline \multirow{2}{*}{ Criteria } & \multicolumn{2}{|c|}{ ES } & \multicolumn{2}{c|}{ CS } \\
\cline { 2 - 5 } & Germination & Emergence & Germination & Emergence \\
\hline \multirow{2}{*}{ RMSEP } & $11 \%$ & $6 \%$ & $4 \%$ & $19 \%$ \\
\hline EF & 0.75 & 0.94 & 0.92 & 0.7 \\
\hline MD & $1 \%$ & $-2 \%$ & $-0.40 \%$ & $-8 \%$ \\
\hline
\end{tabular}

FIGURE 4

Predicted (Pred) and observed (Obs) values of soybean seed germination (Ger) and seedling emergence (Emer) rates at the Auzeville experimental site, with early (ES) and conventional (CS) sowings in 2019. Error bars on the graph represent standard deviation. RMSEP root mean square error of prediction; EF = model efficiency; and MD = mean deviation. 
root length. Average shoot length ranged from 14 to $18 \mathrm{~cm}$ while average root length ranged from 13 to $20 \mathrm{~cm}$.

Nodulation. Average nodule numbers in relation to substrate composition and treatments are reported in Table 3. We observed a significant effect of soil mixture $(P<0.001)$, the treatment type $(P<0.001)$, and the soil mixture-treatment interaction effect $(P<0.001)$ on average number of nodules per plant, which ranged from 6 to 10 . Indeed, independent of the soil mixture, no nodulation was observed in sterilized substrate whereas nodulation, like that observed under field conditions, was observed on nonsterilized soil.

Damping-off incidence and severity. The rates of nonemergence ranged from 0 to $20 \%$. However, nonemergence was mainly due to abnormal growth of radicles or hypocotyls that did not show any characteristic symptoms of damping-off. No symptoms of damping-off disease were observed under growth chamber conditions. Attempts to reisolate the inoculated fungal strain on PDA from root parts did not yield any fungal growth.

Contrast between field and growth-chamber experiments. The maximum germination rates occurred at 10 to 11 das in the growth chamber compared with 37 and 22 das in early and conventional field sowings, respectively (Figs. 4 and 5). The final rates of emergence were higher (from 80 to 100\%) in growth-chamber experiments compared with 72 and $92 \%$ for early and conventional field sowings, respectively. Other early crop growth parameters were greater under growth-chamber experiments compared with those observed in field experiments (Tables 1, 2, 3, and 4). For instance, shoot length at the V1 stage ranged from 9 to $11 \mathrm{~cm}$ in the field versus 14 to $18 \mathrm{~cm}$ in the growth chamber. Likewise, root length at the V1 stage ranged from 9 to $10 \mathrm{~cm}$ in the field versus 13 to $20 \mathrm{~cm}$ in the growth chamber. The average number of nodules per plant was higher in the growth chamber (6 to 10) compared with that

\section{Soil:sand mixture 100:0 (v/v)}

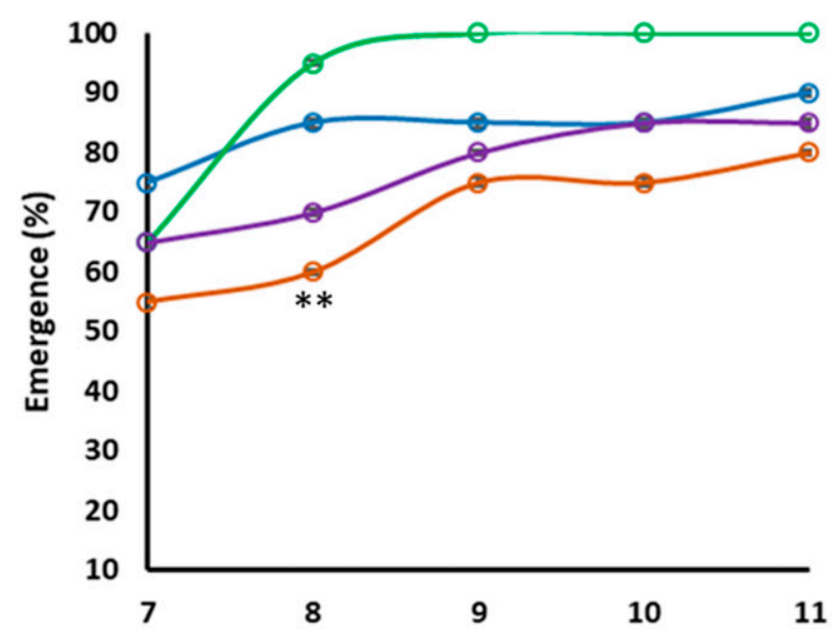

\section{Soil:sand mixture 50:50 (v/v)}

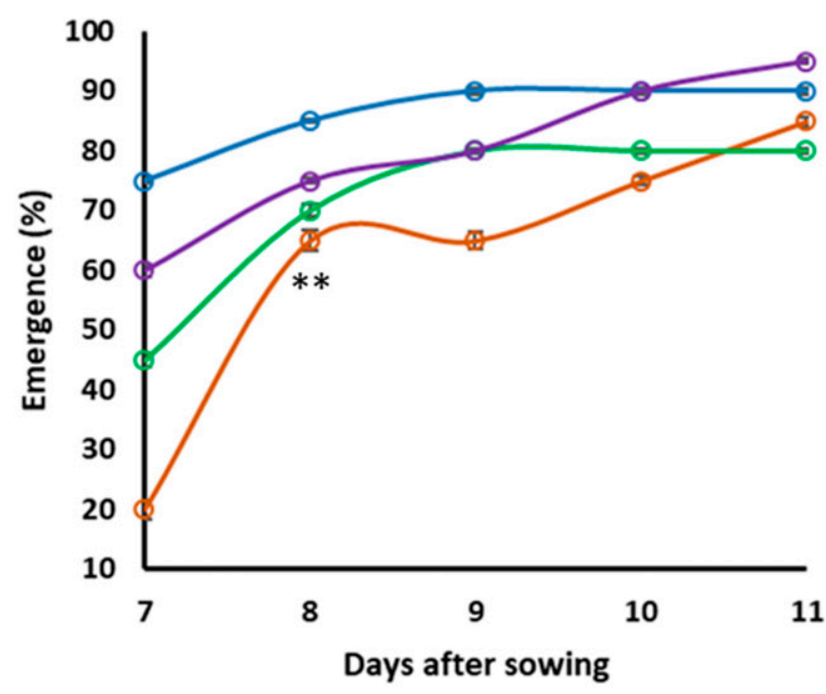

\section{Soil:sand mixture 70:30(v/v)}

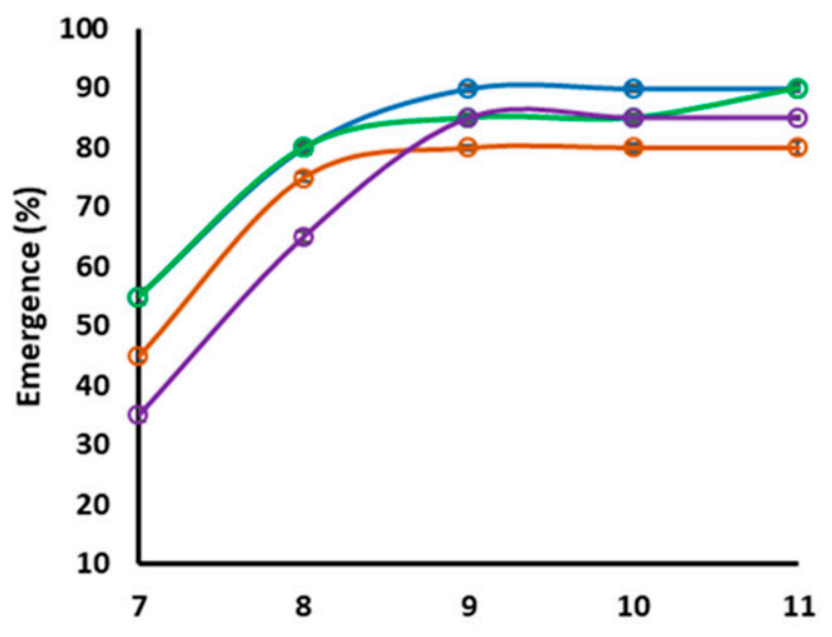

\section{Soil:sand mixture 30:70 (v/v)}

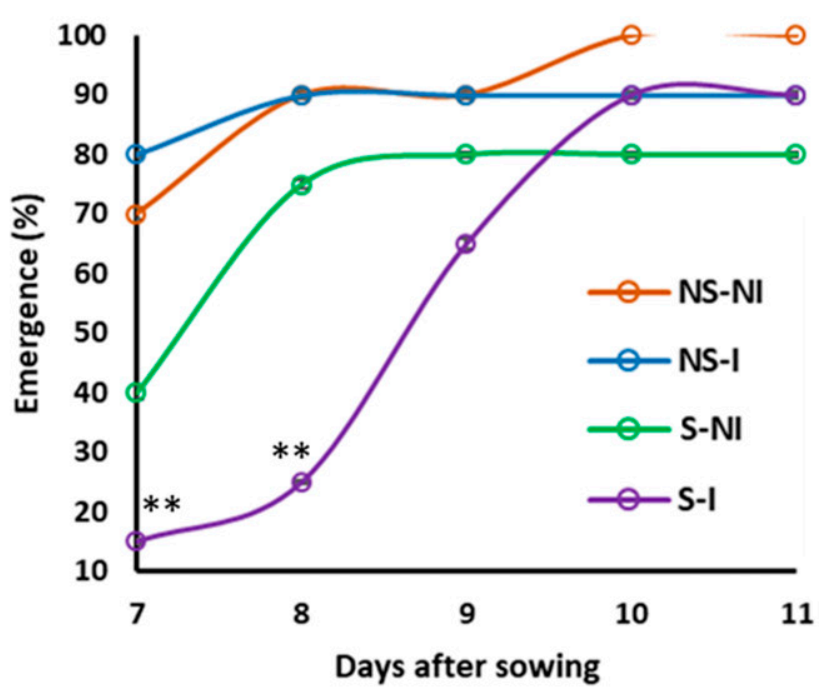

FIGURE 5

Emergence dynamics of soybean as affected by the soil mixture and treatments in growth-chamber experiments. Error bars on the graph represent standard deviation. Asterisks $\left({ }^{*}\right)$ indicate significant differences at $P<0.01$. NS-NI = nonsterilized and noninoculated; NS-I = nonsterilized and inoculated; S-NI = sterilized and noninoculated; and S-I = sterilized and inoculated . 
observed in the field (4 to 6). In contrast, both dry shoot biomass ( $3 \mathrm{~g}$ in the field versus 0.50 to $0.90 \mathrm{~g}$ in the growth chamber) and root biomass ( 0.67 to $0.75 \mathrm{~g}$ in the field versus 0.11 to $0.22 \mathrm{~g}$ in the growth chamber) were higher under field conditions compared with those in the growth chamber.

Model evaluation. Predicted and observed germination and emergence rates for early and conventional sowings are presented in Figure 4. The model finely predicted germination and emergence rates over their courses and final rates compared with the observed values. The predicted and observed final germination rates were 97 and $100 \%$, respectively, for early sowing and 98 and $100 \%$ for conventional sowing. For germination, the prediction quality was very good for both early sowing $(\mathrm{EF}=0.75$,
RMSEP $=11 \%$, and $\mathrm{MD}=1 \%$ ) and conventional sowing $\left(\mathrm{EF}=0.92, \mathrm{RMSEP}=4 \%\right.$, and $\mathrm{MD}=-0.4 \%{ }^{\circ}$. For emergence, the predicted and observed final emergence rates were 77 and $72 \%$, respectively, for early sowing and 85 and $92 \%$ for conventional sowing. As for germination, the prediction quality of the model was equally good for both early sowing $(\mathrm{EF}=0.94$, RMSEP $=6 \%$, and $\mathrm{MD}=-2 \%$ ) and conventional sowing $(\mathrm{EF}=0.70, \mathrm{RMSEP}=19 \%$, and $\mathrm{MD}=$ of $-8 \%)$.

The time to reach the maximum germination rate was 17 das for predicted values and 24 das for observed values for early sowing, whereas it was 6 das for predicted values and 8 das for observed values for conventional sowing. Likewise, time to reach the maximum emergence rate was 43 das for

\section{TABLE 1}

Dry weight of hypocotyl and root of soybean \pm standard deviation as affected by the soil mixture and treatments in growth-chamber experiments ${ }^{\mathrm{Z}}$

\begin{tabular}{|c|c|c|c|c|}
\hline \multirow[b]{2}{*}{ Treatment } & \multicolumn{4}{|c|}{ Soil/sand dilution (vol/vol) } \\
\hline & 100:0 & $70: 30$ & $50: 50$ & $30: 70$ \\
\hline \multicolumn{5}{|l|}{ Dry weight of hypocotyl (g) } \\
\hline NS-NI & $0.50 \pm 0.14 \mathrm{a}$ & $0.62 \pm 0.22 \mathrm{a}$ & $0.67 \pm 0.17 \mathrm{a}$ & $0.62 \pm 0.05 \mathrm{a}$ \\
\hline NS-I & $0.77 \pm 0.05 \mathrm{~b}$ & $0.60 \pm 0.11 \mathrm{a}$ & $0.70 \pm 0.08 \mathrm{a}$ & $0.75 \pm 0.12 \mathrm{a}$ \\
\hline S-NI & $0.75 \pm 0.12 b$ & $0.90 \pm 0.21 \mathrm{a}$ & $0.77 \pm 0.09 \mathrm{a}$ & $0.70 \pm 0.18 \mathrm{a}$ \\
\hline S-I & $0.60 \pm 0.00 \mathrm{ab}$ & $0.67 \pm 0.12 \mathrm{a}$ & $0.80 \pm 0.14 \mathrm{a}$ & $0.75 \pm 0.05 \mathrm{a}$ \\
\hline \multicolumn{5}{|l|}{ Significance level } \\
\hline Soil mixture $(\mathrm{df}=3)$ & \multicolumn{4}{|c|}{ NS } \\
\hline Treatment $(\mathrm{df}=3)$ & \multicolumn{4}{|c|}{$* *$} \\
\hline Soil mixture $\times$ treatment $(\mathrm{df}=9)$ & \multicolumn{4}{|c|}{ NS } \\
\hline \multicolumn{5}{|l|}{ Dry weight of root (g) } \\
\hline NS-NI & $0.12 \pm 0.05 \mathrm{a}$ & $0.20 \pm 0.11 \mathrm{a}$ & $0.17 \pm 0.05 \mathrm{a}$ & $0.20 \pm 0.00 \mathrm{a}$ \\
\hline NS-I & $0.27 \pm 0.05 b$ & $0.12 \pm 0.05 \mathrm{a}$ & $0.20 \pm 0.00 \mathrm{a}$ & $0.20 \pm 0.00 \mathrm{a}$ \\
\hline S-NI & $0.20 \pm 0.00 \mathrm{ab}$ & $0.15 \pm 0.05 \mathrm{a}$ & $0.27 \pm 0.15 \mathrm{a}$ & $0.22 \pm 0.05 \mathrm{a}$ \\
\hline S-I & $0.12 \pm 0.05 \mathrm{a}$ & $0.17 \pm 0.05 \mathrm{a}$ & $0.11 \pm 0.06 \mathrm{a}$ & $0.22 \pm 0.05 \mathrm{a}$ \\
\hline \multicolumn{5}{|l|}{ Significance level } \\
\hline Soil mixture $(\mathrm{df}=3)$ & \multicolumn{4}{|c|}{ NS } \\
\hline Treatment $(\mathrm{df}=3)$ & \multicolumn{4}{|c|}{$* *$} \\
\hline Soil mixture $\times$ treatment $(\mathrm{df}=9)$ & \multicolumn{4}{|c|}{ NS } \\
\hline
\end{tabular}

$\overline{{ }^{z}}$ Means followed by the same letter are not significantly different at $P<0.05$; asterisks $(* *)$ indicate $P<0.01$; NS $=$ not significant; NS-NI $=$ nonsterilized and noninoculated; NS-I = nonsterilized and inoculated; S-NI = sterilized and noninoculated; S-I = sterilized and inoculated; and df = degree of freedom.

TABLE 2

Length of hypocotyl and root of soybean \pm standard deviation as affected by the soil mixture and treatments in growth-chamber experiments ${ }^{2}$

\begin{tabular}{|c|c|c|c|c|}
\hline \multirow[b]{2}{*}{ Treatment } & \multicolumn{4}{|c|}{ Soil/sand mixture (vol/vol) } \\
\hline & 100:0 & $70: 30$ & $50: 50$ & $30: 70$ \\
\hline \multicolumn{5}{|l|}{ Length of hypocotyl $(\mathrm{cm})$} \\
\hline NS-NI & $16 \pm 2 a$ & $16 \pm 1 \mathrm{a}$ & $16 \pm 1 \mathrm{a}$ & $18 \pm 2 c$ \\
\hline NS-I & $17 \pm 2 \mathrm{a}$ & $16 \pm 1 \mathrm{a}$ & $16 \pm 2 \mathrm{a}$ & $16 \pm 2 b$ \\
\hline S-NI & $15 \pm 1 \mathrm{a}$ & $15 \pm 2 \mathrm{a}$ & $16 \pm 2 \mathrm{a}$ & $14 \pm 2 \mathrm{a}$ \\
\hline S-I & $15 \pm 2 a$ & $15 \pm 1 \mathrm{a}$ & $16 \pm 1 \mathrm{a}$ & $14 \pm 1 \mathrm{ab}$ \\
\hline \multicolumn{5}{|l|}{ Significance level } \\
\hline Soil mixture $(\mathrm{df}=3)$ & \multicolumn{4}{|c|}{ NS } \\
\hline Treatment $(\mathrm{df}=3)$ & \multicolumn{4}{|c|}{$* * *$} \\
\hline Soil mixture $\times$ treatment $(\mathrm{df}=9)$ & \multicolumn{4}{|c|}{$* *$} \\
\hline \multicolumn{5}{|l|}{ Length of root $(\mathrm{cm})$} \\
\hline NS-NI & $15 \pm 2 a$ & $18 \pm 3 b$ & $20 \pm 5 b$ & $15 \pm 3 \mathrm{a}$ \\
\hline NS-I & $16 \pm 3 a$ & $15 \pm 2 \mathrm{a}$ & $17 \pm 3 \mathrm{ab}$ & $16 \pm 3 \mathrm{a}$ \\
\hline S-NI & $14 \pm 2 a$ & $16 \pm 2 \mathrm{ab}$ & $15 \pm 2 \mathrm{a}$ & $13 \pm 2 \mathrm{a}$ \\
\hline S-I & $15 \pm 3 a$ & $14 \pm 2 \mathrm{a}$ & $15 \pm 2 \mathrm{a}$ & $15 \pm 4 \mathrm{a}$ \\
\hline \multicolumn{5}{|l|}{ Significance level } \\
\hline Soil mixture $(\mathrm{df}=3)$ & \multicolumn{4}{|c|}{$* * *$} \\
\hline Treatment $(\mathrm{df}=3)$ & \multicolumn{4}{|c|}{$* * *$} \\
\hline Soil mixture $\times$ treatment $(\mathrm{df}=9)$ & \multicolumn{4}{|c|}{$* *$} \\
\hline
\end{tabular}

\footnotetext{
${ }^{\mathrm{z}}$ Means followed by the same letter are not significantly different at $P<0.05$; asterisks $*$, **, and *** indicate $P<0.05,0.01$, and 0.001 , respectively; $\mathrm{NS}=$ not significant; NS-NI = nonsterilized and noninoculated; NS-I = nonsterilized and inoculated; S-NI = sterilized and noninoculated; S-I = sterilized and inoculated; and $\mathrm{df}=$ degree of freedom.
} 
predicted values and 39 das or observed values for early sowing whereas it was 15 das for predicted values and 22 das for observed values for conventional sowing.

There were some differences in terms of predicted versus observed causes of nonemergence. For instance, the model predicted $10 \%$ seedling death due to drought stress in early sowing, whereas no seedling death due to this stress was observed in the field. The model also predicted 3 and $2 \%$ emergence losses due to nongermination for early and conventional sowings, respectively, although we did not observe these losses under field conditions. Finally, we observed $2 \%$ of seedling damage due to soil pests, which was not predicted by the model because the SIMPLE model does not take into account biotic stresses. Finally, predicted and observed seedling losses due to soil clods were 10 and $28 \%$, respectively, for early sowing and 13 and $6 \%$ for conventional sowing.

\section{DISCUSSION}

\section{The fungal pathogen caused severe damping-off disease in vitro but failed to cause disease in the field or growth- chamber experiments}

Inoculation of $R$. solani caused severe damping-off symptoms in vitro. Nevertheless, the application of the same fungal inoculation did not have any effect in field or growth-chamber experiments. The absence of disease development in the field could be due to several reasons, including (i) the low moisture level of the seedbed that did not allow the fungal mycelial growth; (ii) the lack of time for $R$. solani to settle well in the

\section{TABLE 3}

Nodule number observed at the early stage of the soybean root system as affected by the soil mixture and treatments in growth-chamber experiments $^{\mathrm{z}}$

\begin{tabular}{lcccc}
\hline & \multicolumn{4}{c}{ Soil/sand mixture (vol/vol) } \\
\cline { 2 - 5 } Treatment & $100: 0$ & $70: 30$ & $50: 50$ & $30: 70$ \\
\hline NS-NI & $8 \pm 2 \mathrm{~b}$ & $6 \pm 2 \mathrm{~b}$ & $8 \pm 2 \mathrm{~b}$ & $8 \pm 2 \mathrm{~b}$ \\
NS-I & $8 \pm 1 \mathrm{~b}$ & $6 \pm 1 \mathrm{~b}$ & $10 \pm 2 \mathrm{~b}$ & $8 \pm 3 \mathrm{~b}$ \\
S-NI & $0 \pm 0 \mathrm{a}$ & $0 \pm 0 \mathrm{a}$ & $0 \pm 0 \mathrm{a}$ & $0 \pm 0 \mathrm{a}$ \\
S-I & $0 \pm 0 \mathrm{a}$ & $0 \pm 0 \mathrm{a}$ & $0 \pm 0 \mathrm{a}$ & $0 \pm 0 \mathrm{a}$ \\
Significance level & & & $* * *$ & \\
$\quad$ Soil mixture $(\mathrm{df}=3)$ & \multicolumn{5}{c}{$* * *$} \\
$\quad$ Treatment $(\mathrm{df}=3)$ & \multicolumn{5}{c}{$* * *$} \\
$\quad$ Soil mixture $\times$ treatment $\quad(\mathrm{df}=9)$ & & & \\
\hline
\end{tabular}

${ }^{\mathrm{z}}$ Means followed by the same letter are not significantly different at $P<$ 0.05 ; asterisks $(* * *)$ indicate $P<0.001$; NS-NI $=$ nonsterilized and noninoculated; NS-I $=$ nonsterilized and inoculated; S-NI $=$ sterilized and noninoculated; S-I = sterilized and inoculated; and $\mathrm{df}=$ degree of freedom. field, because inoculation was carried out at the time of sowing that might have not provided sufficient time for the fungal pathogen to compete with naturally present microbial populations; (iii) the relatively low density of the inoculum used in the soil, in particular in view of the fact that the inoculated strain was isolated from infected sugar beet and not from soybean; and (iv) the biological suppressiveness of the field soil to $R$. solani.

To test these hypotheses, we conducted the same experiment in a growth chamber, ensuring a constant soil moisture, the same temperature range as that observed for early sowings under field conditions, and an earlier inoculation of the soil with the pathogen (i.e., 1 week before sowing) to ensure its development and establishment. Because several studies highlighted the presence of suppressive soils to different soilborne pathogens, including Pythium ultimum (Bongiorno et al. 2019), Fusarium spp. (Siegel-Hertz et al. 2018), and $R$. solani (Bonanomi et al. 2018), we also investigated the potential soil suppressiveness to the pathogen by mixing the field soil with sand in different proportions and using them both with and without sterilization. Despite all this, no dampingoff disease symptoms were developed, suggesting that, probably, the lack of disease symptoms could be due to reasons other than soil suppressiveness. The absence of disease symptoms under growth-chamber conditions and the lack of pathogen reisolations from the root system likely suggest no pathogenicity of $R$. solani toward soybean or its poor viability when inoculated into the soil. Indeed, although the $R$. solani species complex as a whole has a large host range, individual isolates may have much narrower host ranges. This is in agreement with the fact that the pathogenicity of the fungal isolate used in this study has been previously confirmed on sugar beet but not on soybean. However, we did not attempt to reisolate the inoculated pathogen from the soil to determine whether it was still viable in the soil.

Final emergence rate, nodulation, and plant biomass assessment in early sowing suggest the feasibility of early soybean sowing under conditions in southwestern France

This study showed that soybean final emergence rates mainly depend on seedbed conditions. This corroborates results of the previous study, which showed that the final emergence rate of a given species is more affected by seedbed conditions than by crop genotypes (Constantin et al. 2015; Lamichhane et al. 2020a). Indeed, the high number of days required to reach the final germination ( 24 days or $190 \mathrm{dd}$ ) and emergence (43 days or $315 \mathrm{dd}$ ) rates in early sowing was mainly due to the presence of drought stress in the seedbed. The absence of rainfall up to 3 weeks after sowing led to a situation where three irrigation interventions (days 7, 9, and 15 after sowing) were necessary to avoid complete seed death due to drought, which is very rare in March across our study

TABLE 4

Average nodule, shoot, and root length and their dry biomass per plant under field conditions in early sowing (ES) and conventional sowing (CS) with and without inoculation

\begin{tabular}{|c|c|c|c|c|c|c|c|c|c|c|}
\hline \multirow[b]{2}{*}{ Treatments } & \multicolumn{2}{|c|}{ Nodule number } & \multicolumn{2}{|c|}{ Shoot length $(\mathrm{cm})$} & \multicolumn{2}{|c|}{ Root length $(\mathrm{cm})$} & \multicolumn{2}{|c|}{ Dry shoot biomass (g) } & \multicolumn{2}{|c|}{ Dry root biomass (g) } \\
\hline & ES & CS & ES & $\mathrm{CS}$ & ES & CS & ES & CS & ES & $\mathrm{CS}$ \\
\hline Inoculated & $6.23 \pm 4.40$ & $4.33 \pm 2.61$ & $9.43 \pm 1.86$ & $10.72 \pm 1.30$ & $9.37 \pm 2.23$ & $10.28 \pm 2.25$ & $3.18 \pm 0.27$ & $3.33 \pm 0.25$ & $0.76 \pm 0.09$ & $0.67 \pm 0.07$ \\
\hline Noninoculated & $6.14 \pm 3.76$ & $5.79 \pm 3.51$ & $9.45 \pm 1.25$ & $10.52 \pm 1.30$ & $9.71 \pm 2.16$ & $10.12 \pm 1.86$ & $3.25 \pm 0.28$ & $3.20 \pm 0.38$ & $0.75 \pm 0.06$ & $0.71 \pm 0.08$ \\
\hline \multicolumn{11}{|l|}{ Significance level } \\
\hline Sowing date $(\mathrm{SD})(\mathrm{df}=1)$ & \multicolumn{2}{|c|}{ *** } & \multicolumn{2}{|c|}{$* * *$} & \multicolumn{2}{|c|}{ *** } & \multicolumn{2}{|c|}{ NS } & \multicolumn{2}{|c|}{ ** } \\
\hline Treatment $(\operatorname{Trt})(\mathrm{df}=1)$ & \multirow{2}{*}{\multicolumn{2}{|c|}{${ }^{*}$}} & \multicolumn{2}{|c|}{ NS } & \multicolumn{2}{|c|}{ NS } & \multicolumn{2}{|c|}{ NS } & \multicolumn{2}{|c|}{ NS } \\
\hline $\mathrm{SD} \times \operatorname{Trt}(\mathrm{df}=1)$ & & & \multicolumn{2}{|c|}{ NS } & \multicolumn{2}{|c|}{ NS } & \multicolumn{2}{|c|}{ NS } & \multicolumn{2}{|c|}{ NS } \\
\hline
\end{tabular}

${ }^{\mathrm{z}}$ Values reported \pm standard deviation. Asterisks ${ }^{* * *},{ }^{* *}$, and ${ }^{*}$ indicate $P<0.001,0.01$, and 0.05 , respectively; NS = not significant; and df $=$ degree of freedom. 
site. Unlike for early sowing, better seedbed conditions (a higher seedbed temperature and a higher frequency and quantity of cumulated rainfall) resulted in a faster germination (8 days or $85 \mathrm{dd}$ ) and emergence ( 24 days or $280 \mathrm{dd}$ ) for conventional sowing. This corroborates results of a previous study showing that, under optimal seedbed conditions, germination and emergence of soybean occur very quickly (less than 150 dd for complete emergence) (Lamichhane et al. 2019).

Although the final emergence rate observed for early sowing was lower than that observed for conventional sowing (72 versus $92 \%$ ), this still can be considered sufficient to ensure a good quality of soybean establishment. This is because, unlike corn and sunflower, which cannot compensate for emergence losses during their development, soybean can compensate for the loss of emergence in later stages by branching and its undeterminate or semideterminate growth.

\section{Contrasts between field and growth-chamber experiments suggest lack of optimal seedbed conditions under field conditions for crop emergence and early growth parameters}

As expected, suboptimal seedbed physical conditions, especially in terms of soil moisture, delayed crop emergence under field conditions whereas crop emergence occurred very rapidly under growth-chamber experiments. This can be explained by a lower level of water content of the plant biomass grown under field conditions, due to lower soil moisture availability in the seedbed, compared with those from the growth chamber, where soil moisture was not a limiting factor. Another explanation could be that, in the presence of optimal soil moisture in the growth chamber, shoots and roots tend to develop better than in the field, with suboptimal level of soil moisture. Also, the longer time needed to reach the V1 stage under field conditions (50 and 30 das for early and conventional sowings, respectively) compared with the growth chamber (14 das) might have slowed down development of plant length but not the diametric shoot and root growth, although we did not measure this factor.

\section{Model prediction was very good for germination, emergence courses, and final rates but the prediction rate slightly differed compared with the observed rate in terms of causes of nonemergence}

A comparison of the observed and simulated final germination and emergence rates showed very similar values for the two sowing dates. This is explained by the good prediction quality of the SIMPLE crop emergence model as previously reported for other crops, including soybean (Constantin et al. 2015; Dürr et al. 2016; Lamichhane et al. 2020a). Concerning causes of nonemergence, there were differences between observed (soil clods and soil pests) and simulated (nongermination and drought) values. There are two main reasons for this difference. First, the model predicted the loss of seedlings due to drought in early sowing, because no rainfall occurred up to 3 weeks after sowing. However, the loss of emergence due to drought was not observed because three irrigation interventions were made, which were not necessarily recorded by the sensors installed in the seedbed. This was due to the difference in the amount of irrigated water between the area of field plots where measurements were made and the area where the sensors were installed. As for emergence losses due to soil pests, the SIMPLE model did not predict these losses observed in conventional sowing, because it does not take biotic stresses into account. In addition, this model considers the impact of a soil surface crust and clods separately whereas, in the field, we observed a sort of soil compaction, as previously reported (Lamichhane et al. 2020a), and that is not represented in the model. With regard to nongermination, although a small amount of seed may not germinate for some species, this does not seem to be the case for the soybean cultivar we used, which showed a very good germination capacity, with $100 \%$ seed germinated under field conditions (Lamichhane et al. 2020a).

\section{The quality of soybean establishment may be positively correlated with grain yield under biotic stress conditions}

This study did not investigate the potential correlation between the quality of soybean establishment and grain yield for two reasons. First, a previous study showed no correlation between the quality of soybean establishment and grain yield when biotic stress was not economically important (Lamichhane et al. 2020b). Second, $R$. solani failed to establish under field and growth-chamber experiments. However, future studies that focus on the use of different cultivars and strains of the pathogen, especially those characterized by different virulence levels, should account for sowing date and environmental interaction effect on the crop establishment quality and grain yield.

\section{CONCLUSIONS}

Crop establishment and early plant growth can be affected by several biotic and abiotic factors and their impact can be attenuated by adopting best cropping practices (Lamichhane et al. 2020c). Here, we tested the hypothesis that early sowing used as an agronomic lever to escape summer drought may be favorable for damping-off diseases. Despite in vitro disease development, no damping-off disease symptoms were observed in the field or in the growth-chamber experiments when $R$. solani was inoculated into the soil. It is possible that the fungal strain used, which was originally isolated from sugar beet, is unable to colonize soybean. An alternative hypothesis could be that the fungus lost its aggressiveness when inoculated into the soil. Further investigations that include different $R$. solani strains isolated from different plant hosts, including soybean, may provide insights in this regard.

\section{ACKNOWLEDGMENTS}

We thank D. Marchand, B. Quinquiry, P. Perrin, B. Gleizes, and N. Mbaye for their assistance during laboratory and field experiments; P. Debaeke for his initial feedback on field experiments; C. Steinberg for kindly providing several fungal strains; and l'UMT PACTOLE for supporting the initiative to promote the results presented in this article.

\section{LITERATURE CITED}

Adnan, A. A., Jibrin, J. M., Kamara, A. Y., Abdulrahman, B. L., Shaibu, A. S., and Garba, I. I. 2017. CERES-Maize model for determining the optimum planting dates of early maturing maize varieties in northern Nigeria. Front. Plant Sci. 8:1118. 
Ajayi-Oyetunde, O. O., and Bradley, C. A. 2017. Identification and characterization of Rhizoctonia species associated with soybean seedling disease. Plant Dis. 101:520-533.

Barbetti, M. J., and Sivasithamparam, K. 1987. Effects of soil pasteurization on root rot, seedling survival and plant dry weight of subterranean clover inoculated with six fungal root pathogens. Aust. J. Agric. Res. 38:317-327.

Blunk, S., Bussell, J., Sparkes, D., de Heer, M. I., Mooney, S. J., and Sturrock, C. J. 2021. The effects of tillage on seed-soil contact and seedling establishment. Soil Tillage Res. 206:104757.

Bonanomi, G., Cesarano, G., Antignani, V., Di Maio, C., De Filippis, F., and Scala, F. 2018. Conventional farming impairs Rhizoctonia solani disease suppression by disrupting soil food web. J. Phytopathol. 166:663-673.

Bongiorno, G., Postma, J., Bünemann, E. K., Brussaard, L., de Goede, R. G. M., Mäder, P., Tamm, L., and Thuerig, B. 2019. Soil suppressiveness to Pythium ultimum in ten European long-term field experiments and its relation with soil parameters. Soil Biol. Biochem. 133:174-187.

Broders, K. D., Lipps, P. E., Paul, P. A., and Dorrance, A. E. 2007. Characterization of Pythium spp. associated with corn and soybean seed and seedling disease in Ohio. Plant Dis. 91:727-735.

Brunel, S., Teulat-Merah, B., Wagner, M.-H., Huguet, T., Prosperi, J. M., and Dürr, C. 2009. Using a model-based framework for analysing genetic diversity during germination and heterotrophic growth of Medicago truncatula. Ann. Bot. 103:1103-1117.

Carmona, M. A., Sautua, F. J., Grijalba, P. E., Cassina, M., and PérezHernández, O. 2018. Effect of potassium and manganese phosphites in the control of Pythium damping-off in soybean: A feasible alternative to fungicide seed treatments. Pest Manage. Sci. 74:366-374.

Chang, K. F., Hwang, S. F., Ahmed, H. U., Strelkov, S. E., Harding, M. W., Conner, R. L., McLaren, D. L., Gossen, B. D., and Turnbull, G. D. 2018. Disease reaction to Rhizoctonia solani and yield losses in soybean. Can. J. Plant Sci. 98:115-124.

Constantin, J., Dürr, C., Tribouillois, H., and Justes, E. 2015. Catch crop emergence success depends on weather and soil seedbed conditions in interaction with sowing date: A simulation study using the SIMPLE emergence model. Field Crops Res. 176:22-33.

Dobor, L., Barcza, Z., Hlásny, T., Árendás, T., Spitkó, T., and Fodor, N. 2016. Crop planting date matters: Estimation methods and effect on future yields. Agric. For. Meteorol. 223:103-115.

Dorsainvil, F., Dürr, C., Justes, E., and Carrera, A. 2005. Characterisation and modelling of white mustard (Sinapis alba L.) emergence under several sowing conditions. Eur. J. Agron. 23:146-158.

Dürr, C., Aubertot, J.-N., Richard, G., Dubrulle, P., Duval, Y., and Boiffin, J. 2001. SIMPLE: A model for SIMulation of PLant Emergence predicting the effects of soil tillage and sowing operations. Soil Sci. Soc. Am. J. 65:414-423.

Dürr, C., Constantin, J., Wagner, M.-H., Navier, H., Demilly, D., Goertz, S., and Nesi, N. 2016. Virtual modeling based on deep phenotyping provides complementary data to field experiments to predict plant emergence in oilseed rape genotypes. Eur. J. Agron. 79:90-99.

European Commission. 2018. Report from the commission to the council and the European Parliament on the development of plant proteins in the European Union. https://eur-lex.europa.eu/legal-content/EN/TXT/ ?uri=CELEX\%3A52018DC0757

Fehr, W. R., and Caviness, C. E. 1977. Stages of Soybean Development. Agriculture and Home Economics Experiment Station, Iowa State University of Science and Technology, Ames, IA, U.S.A.

FOP. 2018. La filière soja en France. Fédération Française des Producteurs d'Oléagineux. http://www.fopoleopro.com/la-filiere-soja-en-france/

Gardarin, A., Coste, F., Wagner, M.-H., and Dürr, C. 2016. How do seed and seedling traits influence germination and emergence parameters in crop species? A comparative analysis. Seed Sci. Res. 26:317-331.

Goll, M. B., Schade-Schütze, A., Swart, G., Oostendorp, M., Schott, J. J., Jaser, B., and Felsenstein, F. G. 2014. Survey on the prevalence of Rhizoctonia spp. in European soils and determination of the baseline sensitivity towards sedaxane. Plant Pathol. 63:148-154.

Hothorn, T., and Everitt, B. 2009. A Handbook of Statistical Analyses Using R, 2nd Ed. CRC Press, Boca Raton, FL.

Inokuti, E. M., Thiery-Lanfranchi, D., Edel-Hermann, V., Gautheron, N., Fayolle, L., Michereff, S. J., and Steinberg, C. 2019. Genetic and pathogenic variability of Rhizoctonia solani causing crown and root rot on sugar beet in France. J. Plant Pathol. 101:907-916.

Lamichhane, J. R., Boiffin, J., Boizard, H., Dürr, C., and Richard, G. 2021. Seedbed structure of major field crops as affected by cropping systems and climate: Results of a 15-year field trial. Soil Tillage Res. 206:104845.

Lamichhane, J. R., Constantin, J., Aubertot, J.-N., and Dürr, C. 2019. Will climate change affect sugar beet establishment of the 21 st century? Insights from a simulation study using a crop emergence model. Field Crops Res. 238:64-73.

Lamichhane, J. R., Constantin, J., Schoving, C., Maury, P., Debaeke, P., Aubertot, J.-N., and Dürr, C. 2020a. Analysis of soybean germination, emergence, and prediction of a possible northward establishment of the crop under climate change. Eur. J. Agron. 113:125972

Lamichhane, J. R., Debaeke, P., Champolivier, L., and Maury, P. 2020 b. Combining experimental and modeling approaches to pinpoint genotype $\times$ sowing date $\times$ environment interaction effects on emergence rates and grain yield of soybean. Front. Plant Sci. 11:1358.

Lamichhane, J. R., Debaeke, P., Steinberg, C., You, M. P., Barbetti, M. J., and Aubertot, J.-N. 2018. Abiotic and biotic factors affecting crop seed germination and seedling emergence: A conceptual framework. Plant Soil 432:1-28.

Lamichhane, J. R., Dürr, C., Schwanck, A. A., Robin, M.-H., Sarthou, J.-P., Cellier, V., Messéan, A., and Aubertot, J.-N. 2017. Integrated management of damping-off diseases. A review. Agron. Sustain. Dev. 37:10.

Lamichhane, J. R., You, M. P., Barbetti, M. J., and Aubertot, J.-N. 2020c. Crop Establishment SIMulator: A qualitative aggregative model to predict the role of phytobiomes on field crop establishment. Phytobiomes J. 4:327-339.

Lamichhane, J. R., You, M. P., Laudinot, V., Barbetti, M. J., and Aubertot, J. N. 2020d. Revisiting sustainability of fungicide seed treatments for field crops. Plant Dis. 104:610-623.

Maury, P., Andrianasolo, F. N., Alric, F., Berger, M., Beugniet, G., Chambert, C., Champolivier, L., Doumenc, A., Estragnat, A., Gras, A., Jeanson, P., Jouffret, P., Labalette, F., Thomas, R., Justes, E., and Debaeke, P. 2015. Le semis très précoce: Une stratégie agronomique pour améliorer les performances du soja en France. OCL 22:D503 (in French).

Moreau-Valancogne, P., Coste, F., Crozat, Y., and Dürr, C. 2008. Assessing emergence of bean (Phaseolus vulgaris L.) seed lots in France: Field observations and simulations. Eur. J. Agron. 28:309-320

Pannecoucque, J., Goormachtigh, S., Heungens, K., Vleugels, T., Ceusters, J., Van Waes, C., and Van Waes, J. 2018. Screening for soybean varieties suited to Belgian growing conditions based on maturity, yield components and resistance to Sclerotinia sclerotiorum and Rhizoctonia solani anastomosis group 2-2IIIB. J. Agric. Sci. 156:342-349.

Preece, D. A., Little, T. M., and Hills, F. J. 1982. Agricultural experimentation: Design and analysis. Biometrics 38:524-525.

Rojas, J. A., Jacobs, J. L., Napieralski, S., Karaj, B., Bradley, C. A., Chase, T., Esker, P. D., Giesler, L. J., Jardine, D. J., Malvick, D. K., Markell, S. G., Nelson, B. D., Robertson, A. E., Rupe, J. C., Smith, D. L., Sweets, L. E., Tenuta, A. U., Wise, K. A., and Chilvers, M. I. 2017. Oomycete species associated with soybean seedlings in North America-Part II: Diversity and ecology in relation to environmental and edaphic factors. Phytopathology 107:293-304.

Scholten, O. E., Panella, L. W., De Bock, T. S. M., and Lange, W. 2001. A greenhouse test for screening sugar beet (Beta vulgaris) for resistance to Rhizoctonia solani. Eur. J. Plant Pathol. 107:161-166

Serrano, M., and Robertson, A. E. 2018. The effect of cold stress on damping-off of soybean caused by Pythium sylvaticum. Plant Dis. 102:2194-2200

Siegel-Hertz, K., Edel-Hermann, V., Chapelle, E., Terrat, S., Raaijmakers, J. M., and Steinberg, C. 2018. Comparative microbiome analysis of a Fusarium wilt suppressive soil and a Fusarium wilt conducive soil from the Châteaurenard region. Front. Microbiol. 9:568.

Sneh, B., Jabaji-Hare, S., Neate, S. M., and Dijst, G. 1996. Rhizoctonia species: Taxonomy, Molecular Biology, Ecology, Pathology and Disease Control. Kluwer Academic Publishers, Dordrecht, The Netherlands. 
van Genuchten, M. T. 1980. A closed-form equation for predicting the hydraulic conductivity of unsaturated soils. Soil Sci. Soc. Am. J. 44: 892-898.

Waha, K., van Bussel, L. G. J., Müller, C., and Bondeau, A. 2012. Climatedriven simulation of global crop sowing dates. Glob. Ecol. Biogeogr. 21:247-259.
Wolf, J., Ouattara, K., and Supit, I. 2015. Sowing rules for estimating rainfed yield potential of sorghum and maize in Burkina Faso. Agric. For. Meteorol. 214-215:208-218.

You, M. P., and Barbetti, M. J. 2017. Environmental factors determine severity of Rhizoctonia damping-off and root rot in subterranean clover. Australas. Plant Pathol. 46:357-368. 